\title{
Cuentos tradicionales recopilados en la comarca toledana de la Jara
}

La Jara es una extensa comarca, de unos $2.000 \mathrm{~km}^{2}$, que se halla en el extremo sur-oeste de la provincia de Toledo. Los ríos Tajo y Pusa la limitan por el Norte y el Este, respectivamente; mientras que por el Sur y el Oeste, el límite está formado por las demarcaciones provinciales de Ciudad Real, Badajoz y Cáceres, provincia de la que está separada (que no aislada) por la Sierra de Altamira. Antiguamente, sin embargo, constituyeron este territorio lugares que hoy pertenecen a estas tres provincias ${ }^{1}$.

Poblada desde el paleolítico superior, las presencias romana y árabe pasaron por la zona sin calar prácticamente en ella, dado lo pobre de la tierra. Fueron los repobladores mozárabes primero, castellanos posteriormente, los que desde los siglos XI y XII, y más efectivamente desde el XIII, empezaron a formar los núcleos estables que constituirían los actuales pueblos.

La especial orografía de la comarca, la falta de vías de comunicación que hasta hace bien poco presentaban lamentable estado, hicieron que tuviera como característica cierto conservadurismo que se ha venido manifestando no sólo en el habla, sino también en los medios de producción, por ejemplo. Paradójicamente, en lo que a tradiciones se refiere, la comarca ha perdido muchas de sus antiguas manifestaciones folklóricas, y sólo ahora, que han surgido movimientos de recuperación de lo popular, se han conseguido revitalizar costumbres como las de los carnavales, la quema de Judas (Belvís de la Jara), la soldadesca (Alcaudete de la Jara) o la romería (Aldeanueva de Barbarroya).

En lo referente a esta importante manifestación popular que constituyen los cuentos de tradición oral, hay que señalar que la zona es rica en estas piececillas, si bien su caudal va desapareciendo con la muerte de las generaciones mayores. $\mathrm{Y}$ así como cada vez es menos frecuente oír el rico y

1 Para todo lo relacionado con la comarca son insustituibles los trabajos de F. JiménEZ DE GREGorio. Puede consultarse de este autor su magna obra Los pueblos de la provincia de Toledo (Toledo, 1962-86), 5 vols., especialmente el vol. I. Una breve y clarificadora síntesis se encuentra en su Comarca de la Jara toledana (Toledo: IPIET, 1982). Tanto los datos geográficos como los históricos los extraemos de estas obras. 
preciso vocabulario de nuestros pueblos ${ }^{2}$, porque van desapareciendo los objetos que designaba y porque cada vez más el hombre se va alejando del campo y de las plantas y animales, y, consecuentemente, de sus nombres vernáculos, también con la llegada de los modernos medios de comunicación los cuentos van dejando de cumplir la función que antaño desarrollaban y por ello se van perdiendo ${ }^{3}$.

Hemos seleccionado para esta ocasión una serie de cuentecillos de marcado carácter maravilloso o fantástico, a pesar de que en rigor no todos cumplan las condiciones que los especialistas en la materia postulan. Los ocho cuentos que aquí editamos tienen alguna característica que los transforma en sobrenaturales, ya sea la presencia de un gigante, el que Dios se disfrace de mendigo, que una muda rompa a hablar o que un hombre detenga la bala de un cañón.

No es ahora nuestro propósito plantearnos el alcance del término «maravilloso» aplicado al cuento tradicional. Los grandes estudiosos del género han delimitado ya todas las características de tal denominación ${ }^{4}$. A nosotros nos interesa sólo reproducir una serie de cuentecillos en los que interviene algún elemento sobrenatural, que el informante y la comunidad a que va dirigido el cuento aceptan como propio de una convención pactada y asumida. $\mathrm{Y}$ así como hay otros tipos de cuentos, los de chanzas y anécdotas,

2 La recogida fiel de cuentos tradicionales es fuente inagotable para el conocimiento del habla de la comarca. Una parte importante del léxico ha sido recogida por el autor citado en la nota anterior en los artículos que ha prodigado en el diario $\mathrm{La}$ voz del Tajo, en El Torreón (Alcaudete de la Jara), Juventud (Belvís de la Jara), Trenza (Aldeanueva de San Bartolomé) y otras publicaciones periódicas de la comarca. También puede verse en nuestro artículo «Vocabulario y toponimia de la Jara toledana», Anales Toledanos, XXII (1985), pp. 211-52.

3 Pocas personas hemos encontrado en estos pueblecillos de la Jara que sean capaces de referir más de un cuento; excepcionalmente, los cuentos aquí reproducidos nos los ha contado el informante Valero Gutiérrez, de 91 años, natural de Belvís de la Jara, localidad en la que reside y ha ejercido su profesión de mulero.

4 Sin pretender entrar en la polémica de lo que significa el término «maravilloso», aplicado al cuento tradicional, señalaremos simplemente que el cuento maravilloso es el que se corresponde con una estructura de funciones básicas que ya señalara V. Propp, Morfologia del cuento (Madrid: Fundamentos 1987'), pp. 11-154. Esas funciones admiten variaciones no en lo esencial; para ello véase del autor citado «Las transformaciones de los cuentos maravillosos», en Ibidem, pp. 153-78. Es igualmente útil el estudio preliminar de A. R. Almodóvar a su obra Los cuentos maravillosos españoles (Barcelona: Crítica, $1987^{2}$ ) que divide los cuentos españoles de carácter maravilloso en diferentes categorías: básicos, semi-maravillosos, maravillosos artificiales, etc. Otros estudiosos prefieren la denominación de «de magia», «de encantamiento», «fantásticos», etc. 
según la clasificación establecida s, en los que no se consentiría el menor alejamiento de lo verosímil; este otro tipo, junto con los cuentos de motivo animal, parten de unos presupuestos de credibilidad diferentes.

Nuestra intención ha sido la de contribuir al estudio y catalogación de los cuentos que se oyen en nuestra provincia, sabida la escasez de material recogido y publicado sobre ella ${ }^{6}$. Además, con la publicación fiel del material obtenido mediante grabación magnetofónica, pretendemos servir al conocimiento del habla de nuestra comarca. Sólo nos resta señalar que los cuentos los hemos obtenido en la localidad de Belvís de la Jara, pueblo que se puede considerar como eje y cabeza de la comarca que lleva su nombre.

5 Seguimos los indices más conocidos: The types of the folktale. A classification and bibliography, de Antti AARNE [...] translated and enlarged by Stith THOMPSON, FF Communications n. 184 (Helsinki, 1961) (en adelante AA-T) y el de Ralph S. BoGGS, Index of Spanish folktales, FF Communications n. 90 (Helsinki, 1930). Para las preferencias sobre uno u otro índice, suscribimos las palabras de Julio Camarena en Cuentos tradicionales recopilados en la provincia de Ciudad Real (Ciudad Real: Inst. Estudios Manchegos, 1984), pp. XXI-XXII. Hemos de dejar constancia aquí del agradecimiento a este etnólogo, sin cuya ayuda no hubiera sido posible el presente artículo.

6 La zona castellano-manchega carece de investigaciones sobre la cuentística popular, según ha señalado A. R. Almodóvar, Cuentos al amor de la lumbre, I (Madrid: Anaya, $\left.1987^{6}\right)$, pp. 19-20, con las excepciones de los recogidos por Julio Camarena y, por supuesto, de la ingente labor de Aurelio M. EsPinOSA, Cuentos populares españoles, 3 vols. (Madrid: CSIC, 1946). De Camarena son interesantes «Los cuentos de tradición oral en C-LM», en I Jornadas de estudios sobre el folklore de C-LM (Cuenca, 1982), pp. 87-104, artículo base; también sus artículos «Los cuentos tradicionales en Ciudad Real» y «Sobre un tipo de cuento popular especialmente raro en el occidente europeo», en Narria, 22 (jun. 1981), pp. 36-40 y 27 (sept. 1982), pp. 31-33, respectivamente; «La bella durmiente en la tradición oral ibérica e iberoamericana», RDTP, XL (1985), pp. 259-78; "Algunos mitos clásicos en la tradición oral castellano-manchega», en $2 . "$ Jornadas de Etnología de C-LM (Toledo, 1985), pp. 127-56. Muy interesante como marco de referencia es el artículo de Maxime CHEvalier «El cuento folklórico en C-LM», en Ibidem, pp. 177-83. Véanse también las aportaciones de F. Garcfa PAvón, «Tres cuentos manchegos...», en La Mancha, núm. 1 (enero-marzo 1961), pp. 91-104 y el artículo publicado en la RDTP, I (1944-45), pp. 723-29, que recoge cuentos de Albacete. En lo que se refiere a la provincia toledana en particular señalemos que Aurelio M. EsPinOSA, en sus Cuentos populares españoles, recoge una decena de ellos y José RAMÓN y FERNÁNDEZ OXEA, en su Geografía popular toledana (Madrid, 1965) otros doce, intercalados entre los cantares y refranes que aparecen en la obra; por nuestra parte hemos publicado "Cuentos tradicionales toledanos», en Homenaje a Fernando Jiménez de Gregorio, I (Toledo, 1988), pp. $283-99$ y la ponencia «Cuentos de tradición oral recopilados en la zona suroccidental de la provincia de Toledo», en 5." Jornadas de Etnología de C-LM (Toledo, 1989, en prensa). 
Somos conscientes de que nuestros cuentos no son sino manifestaciones de un fondo folklórico común, aunque alguno de ellos constituya una de las pocas muestras de ciertas versiones conocidas en la península?

\section{PEDRO ZUCIMARRA}

Un señor que tenía un monte y allí cebaba guarros y pensaba de hacerlo con la hija, y aquel gigante decían que era mu feroz; y ese se provino de una perdiz, y se provino de una bola de harina y, claro, pues cebaron los guarros y los vendió y los quitó el rabo a los guarros el criao, y claro, pues fue luego ya y dejó a dos con rabo, al verraco y a la guarra rabeca, y los otros rabos los fue poniendo en un trampal que había, como un barrizal grande, sabes, iba poniendo los rabos, y claro, iba el gigante, tiraba de los rabos, se desprendían los rabos y se caía de culo, y él decía:

-El que tiene fuerza en la muñeca derecha saca la guarra rabeca.

Como sabía ánde estaba la guarra, metía la muñeca y sacaba la guarra. $Y$ entonces el señor gigante se anima a tirar de los rabos y él no sacaba na. Y claro, pues, ya otra vez dice él, dice:

-El que tiene fuerza en el brazo saca el guarro verraco.

Y sacó el guarro y el tío trata con los guarros tirando; pero ya cabreao la dice a una de las hijas:

-Fulana, trae la pala.

Y la hija no le entendió bien, dice:

-Padre, ¿las dos?

Dice:

- Sí, las dos palas.

Y fue el otro el que se lo metió a las dos hijas, como dijo que a las dos, y a las dos hijas el criao...

Luego, como era el gigante el amo, pos le mandaba a las tareas y, claro, le mandó a por agua y, con un pellejo que no podía, y ya pues dice:

-Tú pues cavar estacas al pie de las fuente, con la cosa de llevarlas al pie de la casa.

$\mathrm{Y}$ como se tardaba, pos luego ya fue el gigante y le dijo:

$-¿ Q$ Qué haces, cerril, tonto?

7 Es el caso del cuento LA TORRE HELADA que se reproduce aquí o el de otros que, por espacio, guardamos para mejor ocasión, como el del criado que consigue acostarse con todos los miembros de una familia, o el del rey que «rabió por gachas» y dejó a su hijo la maldición de no envejecer nunca. 
- Pos aquí, clavo unas estacas, cojo la fuente y la llevamos a casa.

$\mathrm{Y}$ fue ya el gigante y llenó el pellejo de agua, se le echó a cuestas y se le llevó. Y luego le mandó a por leña, y tamién tardaba mucho porque no podía con las ramas. Y fue otra vez el gigante y le dejó una rama mu chica, y iba Pedro Zuzimarra con la rama a cuestas gimiendo y fue cuando llegó el gigante y dice:

-Pero, huy, ¿quién anda gimiendo?

Y entonces dijo Perico Zuzimarra, dice:

- Burro que gime, más carga pide.

Y luego ya después de eso dicen que hay que tirar un canto que llegara al pueblo y matara a la más vieja que hubiera en el pueblo, y la más vieja que había en el pueblo era la madre del gigante. De manera que no quiso que ... pero ya tiró el canto y era la perdiz, salió la perdiz «buuh», dice:

-Anda que con la fuerza que lleva el canto si acierta a pegar a mi madre, ya ves...

Y luego ya llega que hay que deshacer, por ejemplo, no me acuerdo qué era, pero en fin, había que deshacer un canto blanco y como él llevaba la bola de harina se lió y deshizo el canto blanco y cuando venía una vez un oso, pos cogió el canto y dice:

- Si llegas acá, pos te pego con el canto y te deshago igual que deshago a este canto.

Y le ganó al gigante. Es que tenían todos miedo al gigante porque el gigante a la vejez a tos los mataba, y él como lo que le mandaba el gigante todo le salía como el gigante quería y si no le salía pos le mataba. Con eso se fue sin darle nada ${ }^{8}$.

8 PEDRo ZUCIMARRA. AA-T 1004, 1045, 1011, 1063B, 1060. Nuestro informante olvida algunos detalles, se confunde y vuelve sobre el cuento inventando otros, a veces sin relación. Se trata del cuento típico de Pedro de Urdemalas, cuyo apellido se deforma (cf. Julio Camarena nos ha comentado haber recogido un cuento cuyo protagonista se llama Pedro Guzimarra, si bien no tiene nada que ver con el de nuestra versión). A. EsPINOSA, hijo, en Cuentos populares de Castilla y León, t. II (Madrid: CSIC, 1988) recoge con el n. 280 PERICO Y EL GIGANTE, versión donde se reproduce el episodio de la fuente, el pinar y los cerdos, pero falta la relación sexual entre Pedro y las hijas del gigante. A. ESPINOSA, op. cit., n.” 163 recoge una versión PEDRO EL DE MALAS, mezclada con otros motivos. Yolando Pino SaAvedra, Cuentos folklóricos de Chile, t. III (Santiago, 1963) recoge con el n. 163 una versión titulada PEDRO ANIMALES, que comparte con nuestro cuento el asedio sexual del gigante hacia sus hijas - tres en este caso-. Es un cuento extendidísimo, ya conocido en el Siglo de Oro, según Maxime CHevalier, Cuentos folklóricos españoles del Siglo de Oro (Barcelona: Crítica, 1983), n. 89 , si bien recoge sólo la alusión al episodio de los árboles. Aurelio de Llano ROZA DE AMPUDIA, Cuentos asturianos recogidos de la tradición oral (Madrid: Caro Raggio, 1925) recoge una 


\section{LA PRUEBA DE LA GRANÁ}

Otra hija de un rey, pues tamién la conquistaban los condes y los marqueses y esa gente y no... y ella no los quería. $Y$ dijo que para casarse con ella el que se casara tenía que hacer un torneo de comerse una graná, grano por grano, a la carrera de un caballo, y el que no se la comiera pos no, no se casaba.

Y no hubo na más que uno que se la comiera. Solo un grano se le cayó de la boca y se le quedó en la barba; pero como se le salió de la boca, pos no valió tampoco.

\section{LA PULGA Y LAS MENTIRAS}

Era un endividuo que tenía cabras y por las mañanas salía de repastro con las cabras, y un día se sentó al sol y sintió un picotazo y era una pulga; la cogió, la mató, la desolló y tendió la piel al sol. Se fue de allí a otro día, estando de repastro con las cabras, se encontró un acibuche, cuyo acibuche tenía dos acitunas; las cogió y las hizo, bajó al pueblo, las hizo y cada acituna le produjo una arroba de aceite. Y con la ojuela pagó la hechura (desperdicio del hueso) y cada acituna le produjo una arroba de aceite y las dos arrobas las echó en el pellejo de la pulga y ya cogió el pellejo de la pulga y le llevaba al pueblo con las dos arrobas de aceite, y a la entrada del pueblo vio una gallina con pollos y la dijo a la dueña que si la vendía un pollo, o se le cambiaba por las dos arrobas de aceite, y la señora le dijo que sí. De manera que la dio las dos arrobas de aceite, se llevó el pollo y se le levó a la majá y cuando llegó a la majá estaba el pollo ya como un burro de grande; montó en él a ver si resestía su peso y cuál fue su sorpresa: cuando estaba más alto que las más altas montañas sintió un golpe en la cabeza, miró pa arriba y eran las puertas del cielo, mira si creció el pollo, de manera que vino San Pedro y le abrió y entró dentro, de manera que entró y le dice San Pedro:

- ¿Tú dónde vas, barrabás?

Dice:

-Allí.

versión con el n. ${ }^{\circ} 44$, titulada UN AMO EXTRAVAGANTE, según la cual un amo sacaba una piel a los criados que no cumplían y cuando llega el hombre listo ordena a un pastor de fuerzas hercúleas y un solo ojo que lo mate, pero el criado consigue burlarle mediante la estratagema de cegarle y salir entre los carneros, para después engañar a su amo enterrando los rabos de los cerdos; también aquí se recoge: «El que tiene fuerza / saca rabo y puerca». Al final el amo le paga su soldada y le envía a su casa. 
Cuando entró había hilanderas, había herreros, había ebanistas, había costureras, en fin, de toda clase, de todo género de artistas. Pero le dijo San Pedro que se bajara otra vez a la tierra antes de que se enterara Nuestro Señor, que a lo mejor le mataba. Y claro, ya el pollo había desaparecío y cómo se bajaba, tú verás, del cielo, y ya le dice San Pedro, dice:

- Mira, ves a onde están las hilanderas y que te den dos ovillos de orillo (lana de dos deos de ancho pa tirantes).

Bueno le dieron dos ovillos de orillo y se eslizó al suelo otra vez, y según venía pa bajo se acabó un ovillo de orillo y añadió el otro, y cuando ya iba a llegar a la tierra le faltaron veinte metros y ya no tenía más orillo, ya no tenía más remedio que soltarse y se soltó y a ónde irás que fue a caer en medio de un melonar. Y pegó con la cabeza en una sandía y se le metió la cabeza en la sandía y claro, pues como tenía la cabeza metía en la sandía pos no podía, así es que echó mano al bolsillo y sacó una navajilla que tenía y la metió en la sandía y cuando rajó la sandía, pues, ya sabes que suelta agua, pues se le metió esa agua en los oídos y se quedó sordo ?

\section{LA HIJA QUE SE QUIERE CASAR}

Esto es un rey que tiene una hija, pero no la apaña nengún marqués ni nengún que la pretende, no quiere a ninguno. $\mathrm{Y}$ al no querer a ninguno acordaron tirar una manzana por lo alto y al que le diera la manzana o el que cogiera la manzana, pos se casaba con ella. Y... aquel día bajaba un cabrero de la sierra y fue el que cogió la manzana, y dice que se tiene que casar con ella. Y dice ella que no, que no se casa, bueno pues, ya dicen que pa que se case con ella tiene que guardar cien liebres en un monte y volver por la noche con ellas al corral sin que falte nenguna, y el hombre ya cuando salió la última, ya no sabía donde estaba la primera, tú verás, cien liebres, y echó a andar por un camino, ya triste y desesperao, y se encontró con una señora en el camino, como si fuera una hada de esas, y le preguntó que qué le pasaba, y se lo contó y entonces le dice la señora esa:

9 LA PRUEBA DE LA GRANA. AA-T 900, 852A. Este cuento aparece combinado con el siguiente, LA PULGA Y LAS MENTIRAS, en A. ESPINOSA hijo, II, n. 224 con el título LA MENTIRA DEL PRINCIPE TUERTO (tipo Aarne-Thompson n. 900 con Boggs n. $852 * A$ ). Nuestro informante los refirió como cuentos independientes. La versión de Espinosa presenta a un príncipe que luego se disfraza de pastor y consigue casarse con la princesa al referir una serie de mentiras. Es cuento conocido en Extremadura, M. CURIEL Merchán, Cuentos extremeños (Madrid: CSIC, 1944), Andalucía (Fernán Caballero) y América. 
- Mira, toma este silbote y tú cuando te vayas o las vayas a recoger no ties que hacer más que tocar este silbote y vienen todas las liebres al corral.

Bueno, pues él se fue y se puso a la sombra de una verde colina, como si fuera un árbol, y allí ya se durmió y ya no se acordaba él de las liebres; pero cuando dispertó, al verse solo otra vez, se acordó del silbote y tocó el silbote y vinieron todas las liebres allá a la pradera, onde estaba él en la verde colina, y por la noche las recogió con el silbote todas al corral. Bueno pues las contaron y estaban las cien liebres en el corral. Y dice ella que no, que no se casa. $Y$ acordaron de que a otro día, cuando fue a soltar otra vez y fueron al campo y a la pradera donde él se ponía a que los vendiera una, a ver si vendiéndoles una pos no los llegaba... Bueno pues estando allí en la pradera llegó un señor con un burro y un cesto y le preguntó que si no vendían liebres allí. Y le dijo: trabajo.

- Pos no señor, aquí no se venden liebres a nadie no siendo por su

Y entonces le dijo el rey que qué trabajo había que hacer, y le dijo que dar un beso al burro, al asno, debajo el rabo, en el culo. Y dio el rey el beso al asno debajo el rabo, le dio la liebre en el cesto y ya venía el rey tan contento, tocó el silbote, brincó la liebre y se salió del cesto y se fue otra vez con las otras.

Bueno pos llegó el rey y dice la hija:

- ¿Qué, papá, qué?

Dice:

- Ay, hija, dice, he llegao y me ha dicho que allí no se venden liebres, menos que no sea por su trabajo y yo pos me he venío.

No dijo el trabajo que había hecho. Dice:

-Pos mañana voy a ir yo, y verá usté cómo...

Bueno, a otro día va la hija con un caballo y un cesto, en fin, bien. Y llega ande están las liebres preguntando que si no vendían liebres y le dijo lo mismo, que allí no se vendían liebres, menos que no fuera por su trabajo. Y preguntó ella que qué trabajo había que hacer, y él la dijo que recoger cagalutas de las liebres en la pradera. Recogió las cagalutas y la dio la liebre; pero hizo lo mismo que con el padre, cuando ya venía con la liebre en el canasto, tocó el silbote y saltó la liebre y se volvió otra vez. Llegó a casa, la preguntó el padre y dijo que nada, que la había dicho que no se vendía allí ninguna liebre, que no se vendían y que no se vendían. Pero ninguno de los dos decían lo que los había pasao. Bueno pues recogió las liebres todas al corral y dice la hija que no, que no se casa, y a ver qué vamos hacer. Dice: 
- Pos mira, le vamos a decir que tie que separar cien fanegas de lentejas de con cien fanegas de guisantes.

Le metieron en el granero y cuando fue a otro día de día ya estaban los guisantes en un montón y las lentejas en otro.

- Bueno pues dice que tampoco se casa, a ver pos qué vamos a hacer ahora, dice, le vamos a meter en una habitación llena de pan, y no vamos a dejar na más que ... el hueco de la persona.

Bueno pues llenaron la habitación de pan, le metieron por la noche en la habitación, tocó el silbote y acudieron ratones, ratones, y cuando amaneció Dios ya se habían comío el pan de la habitación y él llamaba a la puerta que le abrieran. Decía:

-Abrir, abrir, que tengo hambre.

$\mathrm{Y}$ ya cuando abrieron no había en la habitación ni pan ni migas ni na, na más que él. Y dice que no se casa. Pos ya no sabían lo que iban a hacer con él y ya dice la hija dice:

- Mire usté, papá, yo no me caso con él, hay que decirle que nos diga un saco de mentiras.

Bueno se lió a decir mentiras y mentiras, tú verás, el saco no se llenaba, cómo se iba a llenar el saco. Al no llenarse el saco dice:

-Estando yo guardando unas liebres en una verde colina llegó un señor que le vendiera una liebre y yo le dije que allí no se vendían liebres, no siendo menos que por su trabajo. $\mathrm{Y}$ le vendí la liebre y el trabajo que hizo fue dar un...

Ya dijo el padre:

-Ya está casi lleno.

$\mathrm{Pa}$ que no dijera que había dao un beso el rey al burro. Y ya dice:

-Estando yo otra vez en la verde colina fue una señora con la cosa que la vendiera una liebre, y yo la dije que no la vendía una liebre, menos que no fuera por su trabajo. $Y$ ya le dijeron:

- ¿Y qué trabajo hizo?

$\mathrm{Y}$ dice la hija, dice:

-Ya se llenó.

$\mathrm{Pa}$ que no los descubrieran que habían estao recogiendo... Y ahí ya se acabó, pero no tiene fin de casamiento, na más que ahí ya se acaba el cuento ${ }^{10}$.

10 LAS CIEN LIEBRES. AA-T 570. Espinosa hijo, n." 130, recoge versión AA-T n. 610 seguida de AA-T n. 570 , aquí es el hijo tonto de un pastor el que consigue llevar la pera a la hija del rey para salvarla. Espinosa n." 6 recoge el cuento toledano también titulado EL ACERTAJO, que consiste en inventar un acertijo que no adivine la princesa que se va a casar (AA-T n.* 570). También recogido por A. R. Almodóvar, Cuentos 


\section{LA TORRE HELADA}

También era una hija de un rey, que la conquistaban bastantes marqueses, condes, en fin... Pero se titula el de la torre helada, ninguno resestía estar allí toa la noche, porque el que resestiera estar allí toa la noche en la torre helada se casaba con ... Iban condes y marqueses y nada, nenguno resestía, y ya fue Perico, fue Perico y subió la torre y otro Pedro, que era hermano suyo, estaba en un monte y aquel encendió lumbre en el monte y Periquín decía:

- Pedrooo, atiza la candela.

Y claro, resistió toda la noche.

Y dice la hija que no se casa y ya le dice el rey que, claro, que él había resistío toa la noche en la torre helada porque Perico atizaba el fuego, el del monte. Pos ya el rey trató de dar una fiesta, unos invitaos, una comilona, y les dice que tie que ser él el cocinero. Bueno, él es el cocinero y pusieron a los invitaos a una hora, y claro, pos el cocinero puso la lumbre aquí y las calderas en aquella pared, sabes, y claro, llegaba la hora y la comida no... no estaba. Ya los invitaos, cabreaos ya de estar esperando, cada uno se iba a su casa. Ya viene el rey a ver cuándo está la comida, llega a la cocina y la lumbre estaba a un lao y las calderas a otro.

- Hombre, Juan (sic), ¿cómo quieres que...?

Dice:

- Pos sí señor, ya sabe usté que mi hermano tenía la lumbre a una legua de onde yo estaba y usté dijo que porque mi hermano calentaba la lumbre yo resestí toda la noche en la torre helada, de manera que velay usté: las calderas allí y la lumbre aquí. Mire usté a ver las calderas.

$Y$ las calderas estaban frías como cuando las pusieron, de manera que... Y no se casó luego con la hija, lo que lo quedó luego de encargao en todo el cuartel y en todo... Como si fuera él el amo ${ }^{11}$.

al amor de la lumbre, I (Madrid: Anaya, 1983) n. 23 LA ADIVINANZA DEL PASTOR. ROZA DE AMPUDiA, Cuentos asturianos, recoge con los n.os 4 y 132 dos versiones, UN SACO LLENO DE VERDADES y LOS TRES ACERTIJOS recoge una versión en que aparece el motivo de las cien liebres, el beso del rey en el culo y el saco que se llena, en este caso de cosas ciertas. No cabe duda de que el motivo del instrumento musical que domestica animales silvestres pone en contacto nuestros cuentos con otros europeos. $\mathbf{M}$. Josefa Canellada, Cuentos populares asturianos (Salinas: Ayalga eds., 1980) recoge una versión titulada LA ZAMPLOÑ en que ese instrumento rústico hace bailar a las ovejas. $\mathrm{Y}$ en cierto modo pone en contacto nuestro cuento con el Orfeo clásico o con el marinero misterioro del romance tradicional del infante Arnaldos.

11 LA TORRE helADA. Curioso cuento en el cual nuestro informante confunde el nombre de los hermanos protagonistas. Se trata de un cuento recogido preferentemente 


\section{EL HIJO TONTO}

Era una viuda que tiene un hijo y es un gandul que no quiere trabajar, y más bien es así como si se tratara de un poco majareta, sabes, y ya la madre le dice:

- Como no trabajes no vas a comer, y pitos y patos...

En fin que el muchacho le avisaron en una lechería, me paece que era, y fue a trabajar a la lechería y en pago del trabajo le dieron una cacharra de leche. En fin, y la llevaba de la mano y la vertió. La madre le regañó mucho. $\mathrm{Y}$ ya le avisan a trabajar a otro lao y en el otro lao, me paece que le dieron un queso, y se le puso a la cabeza y como estaba el queso recién hecho se llenó toa la cabeza y too. Y la madre le regañó:

- Tú eres tonto; otra vez que te den otra cosa la traes atao y tal.

Ah, porque luego fue a trabajar y le dieron un gato y el gato se le echó a la cabeza y le arañó to. Y la madre le regañó y le dijo:

-Otra vez pues que te den otra cosa sí la atas con una cuerda y la traes a rastro.

Fue a trabajar a casa de un carnicero y cuando acabó el trabajo le dieron una paleta de carne, como le había dicho la madre que si le daban otra cosa que la atara con un cuerda a rastro, pos ató la pierna de carne con la cuerda.

Cuando se fue a su casa en ca su madre llevaba la pierna de carne a rastro. Y la madre lo mismo, le puso perdío. Tú verás, la carne a rastro.

Bueno pues le salió a otro día jornal, me paece que fue con un arriero porque cuando la pierna de carne le dijo la madre que otra vez que le dieran así pa atarlo con una cuerda, que lo llevara al hombro. Y aquella vez fue con un arriero y en pago le dieron un burro y como le había dicho la madre que lo echara al hombro, pos cogió el burro y se le echó al hombro y cuando iba por una calle había una muchacha que era muda y estaba asomá a la ventana y de que le vio ir con el burro a cuestas, echó a reír y a reír y ya rompió a hablar y al romper a hablar pos luego

por versiones sefardíes de Marruecos. A. de LARRea Palacin en Cuentos populares de los judios del Norte de Marruecos, 2 vols. (Tetuán: Ed. Marroquí, 1952-53), aporta dos versiones. La investigadora egipcia R. HABUOCHA en Classification of judeospanish folktales (Baltimore: Maryland, 1973) lo clasifica con el n." ** $926 \mathrm{E}$, si bien se trata siempre de una apuesta entre mancebos y no de conseguir la mano de una princesa, como en nuestra versión. Otras versiones de este cuento aparecen en M. KoEN-Sarano, Kuentos del Folklor de la Famiya Djudeo-Espanyola (Yerushaláyim: Kana, 1986), p. 241 y en la revista $A k i$ Yerushalayim. Israel-La Boz de Israel, n." 5 (1980), pp. 50-1. (Debemos estos datos a la gentileza de Julio Camarena). 
los padres le premiaron y los casaron a los dos, y luego ya la viuda se fue a vivir con los ricos y él y ahí mi cuento se acabó ${ }^{12}$.

\section{JUAN SOLDAO}

Esto era un soldao en los tiempos de otras veces, de otros siglos, y le habían mandao con permiso a su pueblo, y entonces no andaban las perras, andaban los cuartos, y le mandaron con tres panecillos y tres cuartos; y en aquella época tampoco había coches pa transportes y cosas, y cuando iba ya pa su casa pues salieron dos pobres a pedirle una limosna, y entonces dice él, dice:

- ¡Mecagüen Dios! ¿Es que con tres cuartos y tres panecillos que me han mandao a mi casa queréis que sus dé una limosna? Me paece que no, mecagüen Dios.

Y los pobres eran Dios y San Pedro. Pero, en fin, ya dice:

-Bueno pues sus voy a dar un panecillo pa que veáis que...

Los dio un panecillo y un cuarto y se fueron. Y el soldao siguió. Ya a más distancia salen otra vez a él, otra vez a pedirle más limosna, dice:

- ¡Mecagüen Dios! ¡Cuántos pobres hay aquí en esta tierra! Ya han salío otros dos a mí y he tenío que dar un pan, un cuarto y un panecillo; pero en fin, tomar vosotros otro cuarto y otro panecillo y ahora ya no me quedo con más que con un cuarto y un panecillo.

Bueno pues se retiraron. Más alante salen otra vez a él a pedirle limosna y ya allí hablándolos mal y diciéndolos muchas cosas, dice:

-Bueno, dice, lo que podemos hacer con este cuarto y este panecillo ya es irnos tos juntos.

Bueno pues se van tos juntos y llegan ahí cerca de Oropesa, y había allí un pastor y tenía borregos, y le dice Dios al soldao, dice, pero el soldao no sabía que eran Dios ni San Pedro, a Dios le llamaba él, un mote le ponía muy feo. Y le dice Dios que vaya por un borrego, «Pelele» le llamaba. Dice Pelele, dice:

-Ves a por un borrego allí, bolo, y nos llevamos pa comer.

$\mathrm{Y}$ el soldao dice:

- ¿Qué irías tú?

Dice:

- Anda, ves tú, bolo, si el pastor no te ve ni los perros.

12 EL HIJO TONTO. AA-T 1696, 571. Similar a otras versiones en que un tonto hace algo que consigue hacer hablar o reír a la hija de un rey o personaje rico, como en este caso. Versiones parecidas se pueden ver en Espinosa hijo, n. 371 y siguientes. 
Bueno pues ya se arrancó a por el borrego, se le trajo y llegaron al pueblo y Dios y San Pedro se fueron a pedir, se fueron a pedir y él se quedó guisando el borrego y se comió las asaúras. Y, claro, pues les habían dao bastantes perrillas, en fin, que se pusieron a comer y como eran Dios y San Pedro sabían toas las faenas, pues ya que estaban comiendo dice Dios a San Pedro, dice:

-Oyes, ¿tú no te has encontrao ningún, ningún cacho de asadura?

Dice San Pedro, dice:

-Yo no.

$Y$ dice el militar:

-Coñe, contra más viejos sois, más tontos, ¿no sabéis vosotros que los borregos negros no tienen asaúra?

Pues ya de que comieron dice Dios, Pelele, que van a partir las perras de lo que han pedío y Pelele, eran tres y hacía cuatro montones y se lo esbarataba. Hacía cuatro montones y el soldao se lo esbarataba. Bueno pues ya una vez dice Pelele:

-Déjame hombre, déjame, déjame que haga los cuatro montones.

-Que no quiero, que...

En fin, hizo los cuatro montones. Ya que hizo los cuatro montones le dice a San Pedro, dice:

- Mira, esto pa ti, esto pa el soldao y este pa mí.

-Y el que queda ¿pa quién va ser?

- Hombre, dice, el que queda se le daremos al que se ha comío las asaúras del borrego negro.

-Entonces pa mí.

Bueno pues ya se fueron y según iban otra vez hacia Madrid vieron un rastrojo quemao y Pelele dijo que si le daban una cantidad que él lo ponía como estaba antes. Y le dijeron que sí, y, claro, pues, él como iba con ellos pos le vio de hacer las cruces, de hacer las cosas y se puso otra vez el rastrojo como estaba antes y lleno de haces. Le dieron una cantidad bastante grande y siguieron pa alante y al llegar a Madrid dijeron que la hija del rey estaba muriéndose y fueron a salvala y claro, pos entonces el soldao le decía a Dios:

- Pelele, a este pídele mucho. Este es el que me ha mandao a mí con los tres cuartos y los tres panecillos. Tú pídele mucho, que este...

En fin, le pidió lo que le pareció y decía el soldao que era muy poco. Y mandó traer un haz de leña y echar encima del haz de leña a la hija, y amecharon el haz de leña y Dios hizo las cruces y San Pedro y revivió la hija del rey. Y les dieron mucho, pero ya ahí se separaron; Dios y San Pedro se fue por un lao y él ya se quedó solo, y como había visto de hacer a Pelele las cosas que hacía, pos él quería hacer lo mismo y llegó a 
un pueblo y había una defunta, que quiso hacer lo que había hecho Pelele con la hija del rey. Preparó un haz de leña y la echó en lo alto del haz de leña, le amechó y venga a hacer cosas y santiguarse y pitos; pero que la defunta no revivía, de manera que le metieron en la cárcel y estando en la cárcel, como to lo sabía Dios y San Pedro sin él saber quién eran, pos pasaron por allí y le vieron y le sacaron. $Y$ entonces fue cuando le dijo Pelele que él no podía hacer lo que él, porque Pelele era Dios y el otro era San Pedro, de manera que le dejaron todo el dinero que tenían y él salió de la cárcel y se fue otra vez a su casa y mi cuento se acabó ${ }^{13}$.

\section{LA JIGUEROLA}

Esto era uno que iba buscando trabajo y encontró trabajo en casa de uno que tenía que ir a cavar a una viña, y en la viña había una jiguerola, una higuera. Bueno pues el primer día le mandaron a la jiguerola, a la viña, con una pan de merienda. Llegó a la jiguerola, que estaba en medio de la viña, y dijo:

- Según se come se trabaja.

Tendió la manta en el suelo y se tumbó hasta por la tarde, que fue en casa del amo. Otro día, cuando fue por la noche, le preguntó que hasta dónde había llegado, dice:

- Hasta la jiguerola.

Y decía el amo:

- Joder, si ha empezado por una punta ha llegao al medio. En fin...

A otro día vuelve con la misma merienda y llega a la jiguerola y dice:

-Según se come se trabaja. Tumba que tumba.

Viene por la noche.

- ¿Hasta ónde has llegao hoy?

13 JUAN SOldao. AA-T 753, 785. Recogido por Camarena n. 66 (tipo 300 mezclado con 753 y 785) en que el soldado consigue llegar al cielo después de una serie de peripecias. También recogido por Espinosa n. ${ }^{\circ} 168$, donde también el protagonista sube al cielo después de quemar a los demonios. Asimismo lo recoge Curiel con el título JESÚS, SAN PEDRO Y EL MILITAR, una versión cercana a la nuestra, de Herrera del Duque. Joaquín DIAZ y Maxime CHEvalier, Cuentos castellanos de tradición oral (Valladolid: Ámbito, 1985) recogen una versión de este cuento, n. ${ }^{\circ} 22$, donde Juan se encuentra con un rey, no con Dios, el cual le concede diversas mercedes. Aurelio de Llano recoge una versión con el n. ${ }^{2} 118$ donde el soldado se encuentra sólo a San Pedro, el cual le concede tres deseos con los que consigue vencer al diablo y llegar al cielo. También recogido por Fernán Caballero, Cuentos andaluces, ed. y est. de A. Soria (Madrid: Ed. Alcalá, 1966), p. 115 con el n. ${ }^{\circ}$ x, si bien el protagonista consigue un zurrón mágico; con él consigue vencer a Lucifer y llegar al cielo. Faltan secuencias de nuestra variante y se mezclan otras de cuentos diferentes. 
- Hasta la jiguerola.

-Joder, este pronto acaba la viña. Hoy a la jiguerola también.

Pero ya al tercer día fue hasta la jiguerola y dice:

- Según se come se trabaja.

Él necesitaba comer más de lo que le daban. A otro día dice el amo a la criada, dice:

- Mira, te vas a ir tras de él, asoma y traspón, a ver qué es lo que hace.

Pues se va, asoma y traspón, y llega a la jiguerola y tiende la manta y dice:

- Según se come se trabaja. Tumba que tumba.

$Y$ ya viene la criada y dice:

- ¿Qué?

- Pos mire usté, llega hasta la jiguerola y dice: «según se come se trabaja» y tiende la manta en el suelo y se tumba a descansar.

Bueno, viene por la noche, y ya estaba enterao el amo. Dice:

- ¿Hasta ónde has llegao hoy?

- Hasta la jiguerola.

Dice el amo, dice:

- Pos ya poco le queda.

A otro día le dan bien de almorzar, bien, y tres panes de merienda y entonces pidió otra azá más y llegó a la jiguerola y soltó la manta y cogió las dos azás, y dice:

- Según se come se trabaja.

Y trabajaba con las dos azás, una en cada mano. Por qué coñe no va por allí el rey de cacería y tiraron a un venao y fue a caer delante de donde estaba cavando él con las azás.

Bueno, pos le dijeron que se fuera con ellos y se fue con ellos y al irse con ellos ya, pues le cogieron miedo, de las cosas que hacía. Le mandaron al Pardo, si sabes aónde está, con dos pares de bueyes y una carreta a hacer leña, y cuando estaba haciendo la leña acudieron los lobos y le mataron los bueyes y él dijo:

- Pos como me llegue a bajar del árbol, ya veremos a ver lo que pasa.

En fin, ya que le habían matao los bueyes los lobos se bajó y cogió a cuatro lobos y los enganchó a la carreta y trajo una carreta de leña a palacio. Ya empezaron a cogerle miedo y acordaron de llevarle al campo de tiro, que hoy ya está poblao, en Retamales (ya por allí ya todo es Madrid, que allí iba yo al tiro), y dicen cuando ya esté allí va a ir una compañía de infantería y cuando vaya le descargan, de manera que cuando fue a Retamales le soltaron una descarga y dice:

-Joder, cuántas avispas hay por aquí. 
Silbaban las balas... En fin, que volvió otra vez a palacio y ya estaban aburríos y acordaron de que a otro día fuera la Artillería, a ver si ... Le mandaron otra vez y mandaron la Artillería y según le soltaban el cañonazo, según iba el proyectil le pegaba con la mano, le devolvía otra vez a los cañones y mataba a los soldaos. Pues ya se vinieron y no le mataron, devolvía los proyectiles y no... Y ya no sabían lo que iban a hacer con él, con esa potencia y esas cosas ... Y ya se hizo amigo de un corneta y el corneta pues los dijo que él se atrevía a matarle.

- ¿Tú?

-Sí.

- Vamos a verlo.

Y el corneta preparó un mono de pez y según iban de paseo una vez, le dice:

-Oyes, mira, aquel negro me ha dicho que te va a hacer, que te va a acontecer.

Dice:

- ¿Ese? A ese como le meta yo un puñetazo entre ojos.

Le llevó hasta onde estaba el negro de pez, le pegó el puñetazo y se le quedó el puño pegao dentro de él, luego el otro puño, en fin, luego ya se le quedaron los cuatro ramos, porque luego ya le iba a dar una patá y entonces fue cuando le pudieron matar y mi cuento se acabó ${ }^{14}$.

\section{ABRAHAM MADROÑAL DURÁN \\ Seminario de Lexicografía. \\ Real Academia Española}

14 LA Jiguerola. AA-T 175, 6500. Es el célebre cuento del «Muñeco de brea», tan bien estudiado por Aurelio M. EsPINOSA, op. cit., el cual estudia 318 versiones de las cuales considera como privativas de la península el tipo III en el que los protagonistas son seres humanos y el muñeco de brea artificial. El protagonista es un hombre arrogante, casi malhechor, de habilidad y fuerza extraordinarias. Camarena recoge PERICO CATORCE, EL SEGADOR, tipo AA-T 650, en el que el protagonista vence incluso a los demonios y se casa al final. También Joaquín DiAz, op. cit., n. ${ }^{\circ} 11$, además, recoge una versión titulada EL HOMBRE DE PEZ (n. 10 ) donde el protagonista no es un hombre de fuerza descomunal, sino un valentón que al ir a tocar las campanas es castigado por el muñeco de brea; pero no acaba con la muerte (AA-T 175 mezclado con 326, «Juan sin miedo»). 
«Cuentos tradicionales recopilados en la comarca de la Jara» es una nueva recogida de esta importante manifestación folklórica que es el cuento de tradición oral. Recopilación que apenas cuenta con antecedentes en la provincia de Toledo. Se publican aquí ocho cuentecillos de marcado carácter fantástico, grabados en la localidad de Belvís de la Jara. Merced a las oportunas notas los cuentos son clasificados según los Indices generalmente aceptados y encuadrados dentro de la tradición folklórica española y americana.

"Traditional tales collected from the region of La Jara» is a new collection of this important popular manifestation which is the traditional oral tale. The collection, practically the first of its kind from the province of Toledo, contains eight tales (all with strong features of fantasy), recorded at the village of Belvís de la Jara. Through the appropriate notes, the tales are classified according to the widely accepted indices of the Spanish and American folklore tradition. 